Supporting Information

\title{
Centrifugal Paperfluidic Platform for Accelerated Distance-Based Colorimetric Signal Readout
}

Kento Maejima, Yuki Hiruta and Daniel Citterio*

Keio University, Department of Applied Chemistry, 3-14-1 Hiyoshi, Kohoku-ku, Yokohama, Kanagawa, Japan

*To whom correspondence should be addressed.

Email: citterio@applc.keio.ac.jp

\section{Table of Contents}

Abbreviations

Reagents

Evaluation of CD-PAD accuracy for assaying "unknown" $\mathrm{Ni}^{2+}$ samples

Figure S-1. Schematic illustration of breadboard connection for rotary system.

Figure S-2. Arduino sketch code for optimized spinning protocol.

Figure S-3. Illustration of wax printed pattern on filter paper.

Figure S-4. Illustration of cutting pattern of lamination films.

Figure S-5. Alignment of printed paper sheet and pre-cut lamination film.

Figure S-6. Influence of rotational velocity on colored length in a distance-based $\mathrm{Ni}^{2+}$ assay.

Figure S-7. Liquid leakage at wax valve.

Figure S-8. Detection chemistry of $\mathrm{Ni}^{2+}$ with DMG.

Figure S-9. Calibration curve of $\mathrm{Ni}^{2+}$ assay with extended concentration range.

Figure S-10. Correlation between "true" and measured $\mathrm{Ni}^{2+}$ concentration values of aqueous standard solutions using CD-PADs.

Figure S-11. Photograph of a CD-PAD after simultaneous assay of 24 identical samples.

Table S-1. Pin functions of motor driver (Toshiba TA7291P).

Table S-2. Pin functions of Arduino Uno R3

Table S-3. Optimized rotation protocol for each type of chamber.

Table S-4. Influence of sample volume on colored length and reproducibility.

Table S-5. LODs for $\mathrm{Ni}^{2+}$ assays performed on CD-PADs with different sample chambers

Table S-6. Benchmark of analytical performance.

Table S-7. Benchmark of cost.

Table S-8. Assay results for "unknown" aqueous $\mathrm{Ni}^{2+}$ solutions obtained with CD-PADs.

References 


\section{Abbreviations}

UV: Ultra-violet

CD: Compact disc

DVD: Digital versatile disc

BD: Blu-ray disc

COP: Cyclo olefin polymer

PMMA: Poly(methyl methacrylate)

USD: United States Dollar

DC: Direct Current

ICP-OES: inductively coupled plasma-optical emission spectroscopy

ICP-MS: inductively coupled plasma-mass spectroscopy

3D: three-dimensional

DMG: Dymethyl glyoxime

LOD: Limit of detection

$\mathrm{CV}$ : Coefficient of variation

PWM: Pulse width modulation 


\section{Reagents}

Ultrapure water $\left(>18 \mathrm{M} \Omega \mathrm{cm}\right.$ ) was obtained from a Direct-Q ${ }^{\circledR}$ 3UV ultrapure water purification system (MilliporeSigma, Burlington, MA) and used for the preparation of all aqueous solutions.

2-Propanol (IPA) was obtained from Nacalai Tesque (Kyoto, Japan). Tris(hydroxymethyl)aminomethane (Tris), hydrochloric acid $(\mathrm{HCl})$ and nickel chloride $\left(\mathrm{NiCl}_{2}\right)$ were obtained from FUJIFILM Wako Pure Chemical Industries (Osaka, Japan). Dimethylglyoxime (DMG) and trisodium 2-hydroxy-1-(4-sulfonato-1-naphthylazo)naphthalene 3,6-disulfonate (Amaranth) was purchased from MilliporeSigma (Burlington, MA).

\section{Evaluation of CD-PAD accuracy for assaying "unknown" $\mathrm{Ni}^{2+}$ samples}

To evaluate the accuracy of the CD-PAD assay, the MV sample metering chamber data of Figure 5 of the main text was used. A calibration curve was created using a subset of the data of Figure $5\left(100,400,800,1200,2000\right.$ and $3,000 \mu \mathrm{M}$ of $\mathrm{NiCl}_{2}$ standard solutions) $(\mathrm{n}=4)$. The other measured standard solutions $\left(200,600,1000,1500\right.$ and $\left.2500 \mu \mathrm{M} \mathrm{NiCl}_{2}\right)$ were treated as a set of "unknown" samples (n=4). 


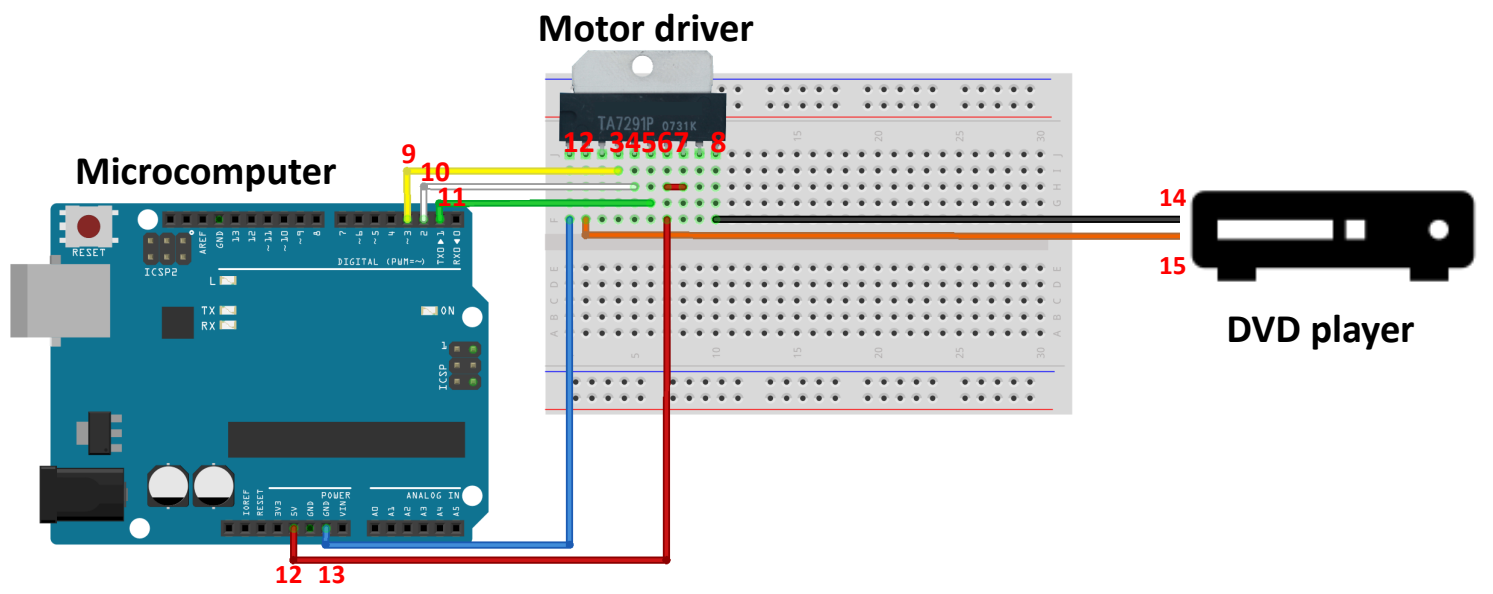

Figure S-1. Schematic illustration of breadboard connection for rotary system. 


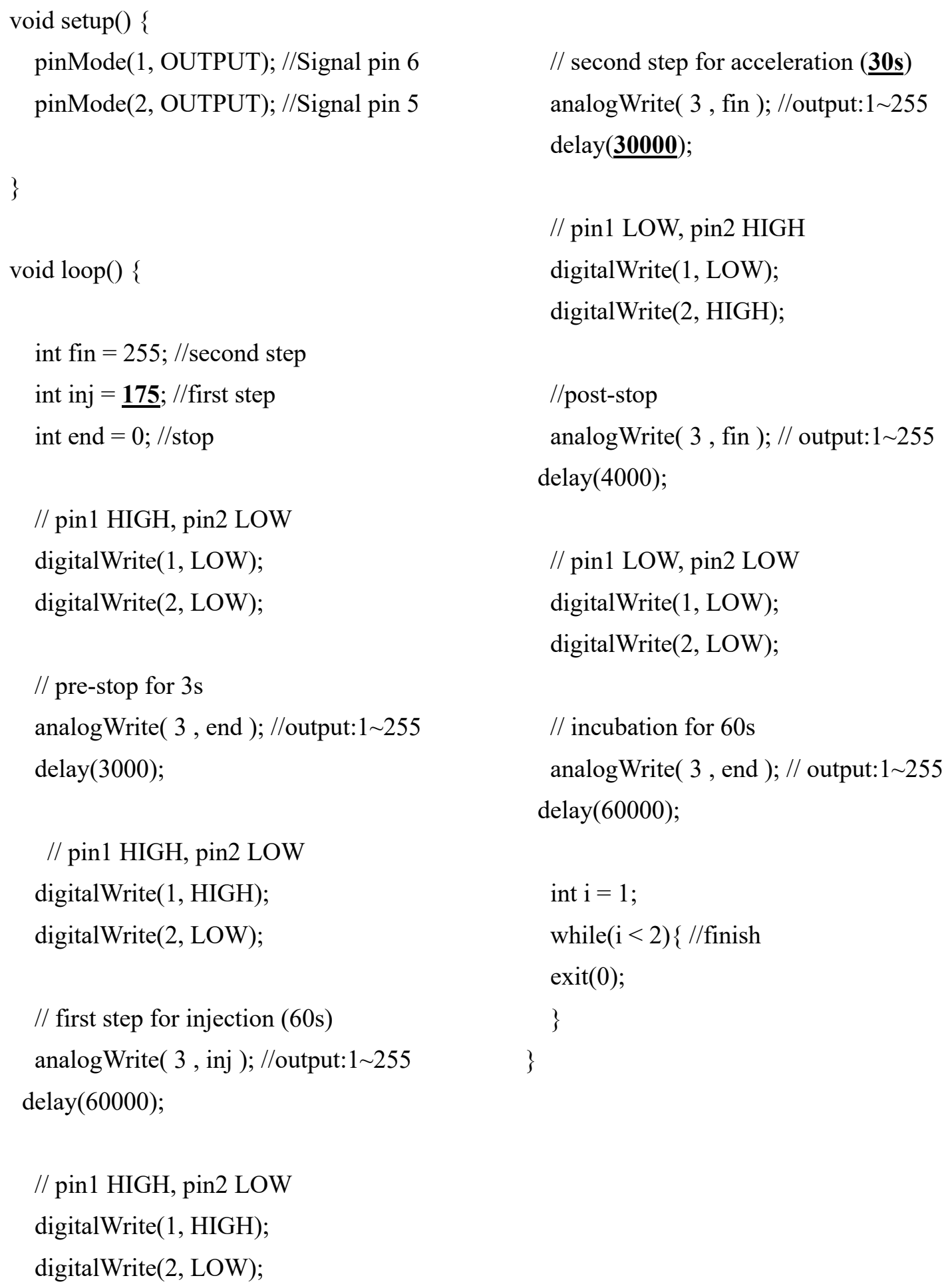

Figure S-2. Arduino sketch code for optimized spinning protocol of SV/MV. The bold and underlined values can be changed for each optimal protocol or investigation. 
(A)

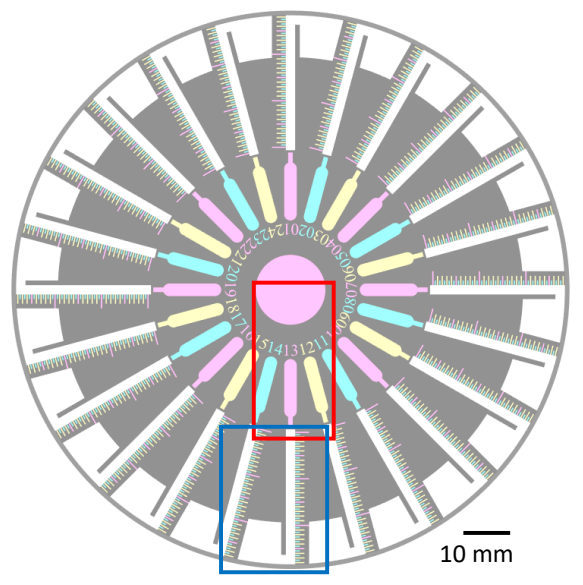

(B)

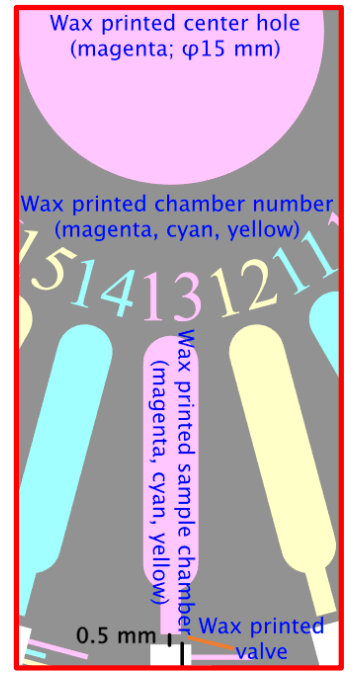

(C)

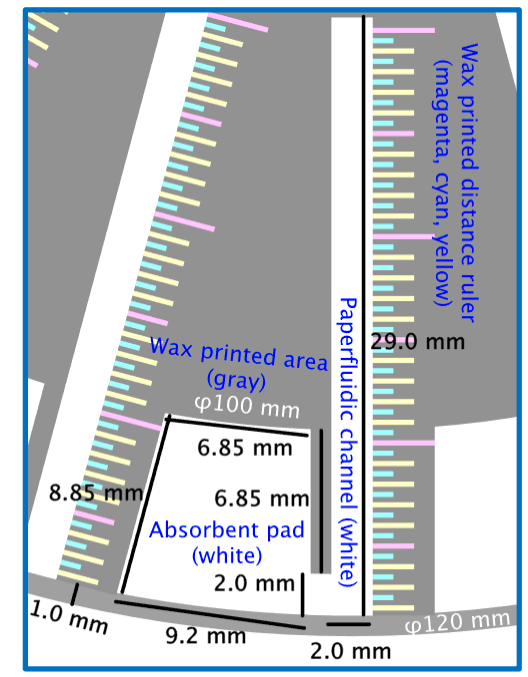

Figure S-3. Schematic illustration of the wax printed pattern on filter paper. White areas indicate non-printed areas. A single unit including chamber, chamber number, valve, channel, ruler and absorbent pad is circularly replicated to achieve a total of 24 units on one disk. (A) The entire wax printing design of the disc-shaped filter paper. Red and blue rectangles indicate the areas enlarged in (B; red) and (C; blue). (B) Detailed illustration of the center area of the disc-shaped paper. Information on the dimensions of sample chambers is given in Figure 3-C of the main text. (C) Detailed illustration of the outer area of the disc-shaped paper. 

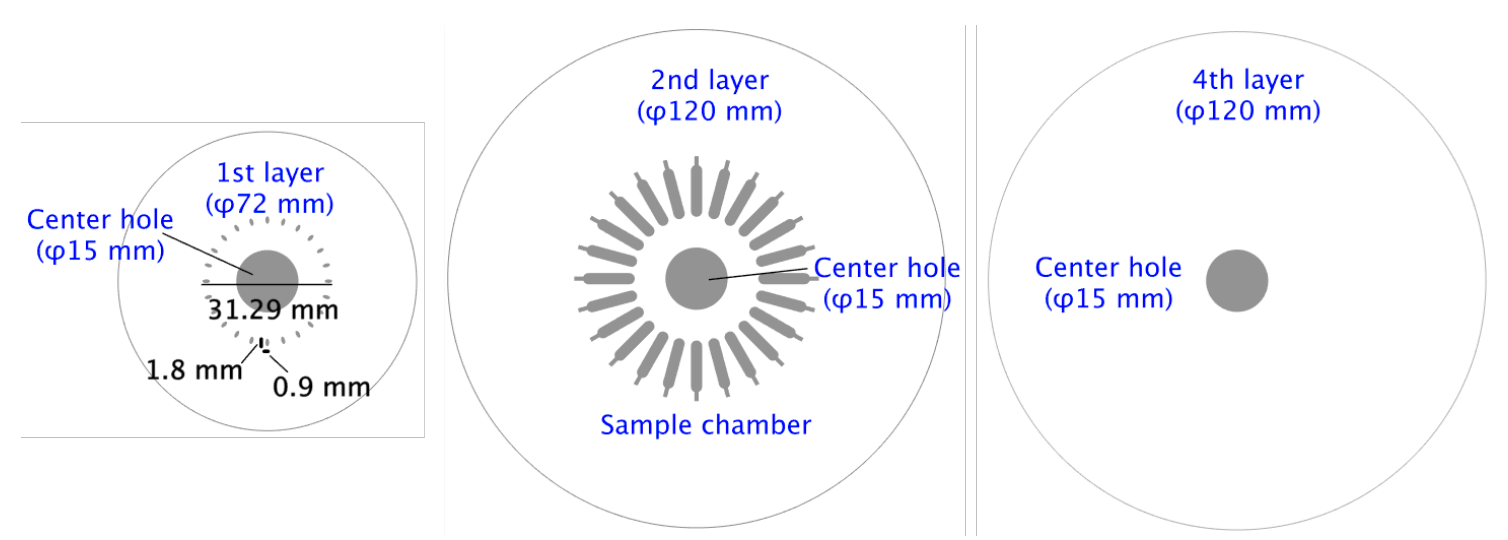

Figure S-4. Schematic illustration of the cutting patterns of lamination films. Gray areas are cut out by the auto-cutter. 


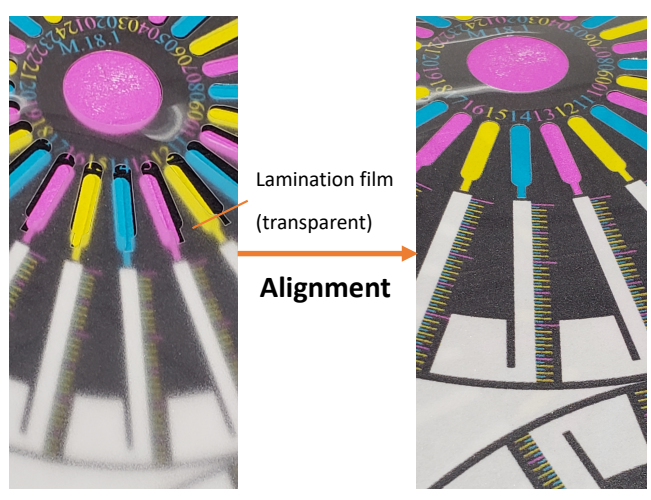

Figure S-5. Photograph of alignment of printed paper sheet and pre-cut lamination film. Both dimensions are accurate and can readily be aligned by hand. 


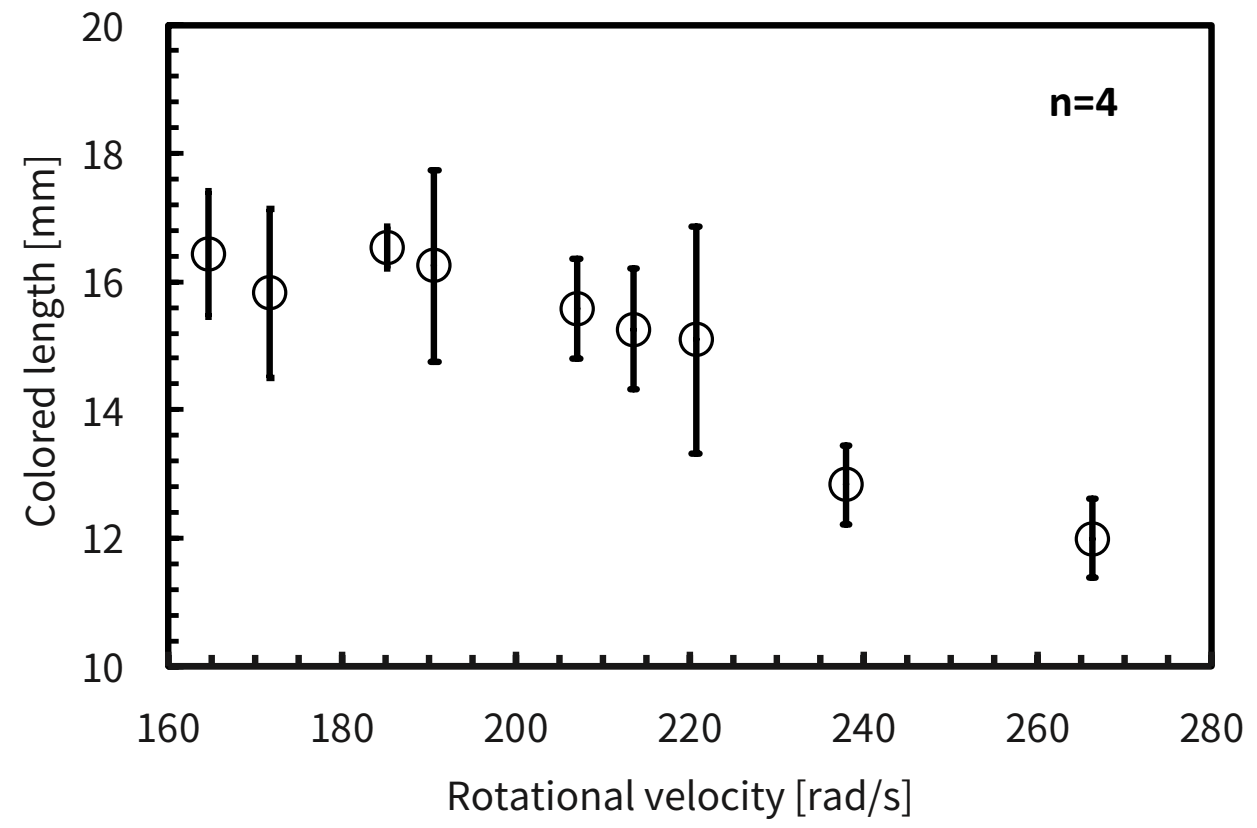

Figure S-6. Influence of rotational velocity on colored length in a distance-based $\mathrm{Ni}^{2+}$ assay $(2$ $\mathrm{mM} \mathrm{NiCl} 2)$ in paperfluidic channels with deposited DMG indicator $(\mathrm{n}=4)$. 


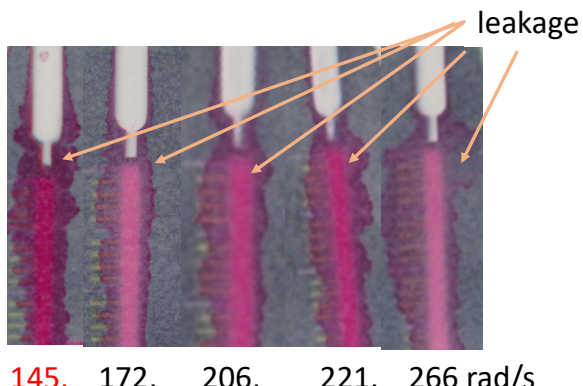

Figure S-7. Photograph of penetration of food dye solution ( $2 \%$ amaranth) between paper substrate and lamination film around the wax valve. Various rotational velocities between 145 $266 \mathrm{rad} / \mathrm{s}$ for the initial minute were studied, followed by rotation at $266 \mathrm{rad} / \mathrm{s}$ for additional 2 minutes. 


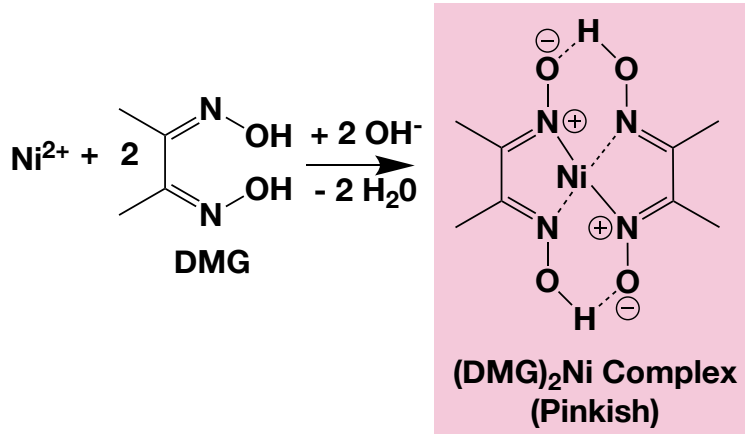

Figure S-8. Detection chemistry of $\mathrm{Ni}^{2+}$ with DMG. DMG itself is colorless, while it forms a pinkish $(\mathrm{DMG})_{2} \mathrm{Ni}$ complex. 


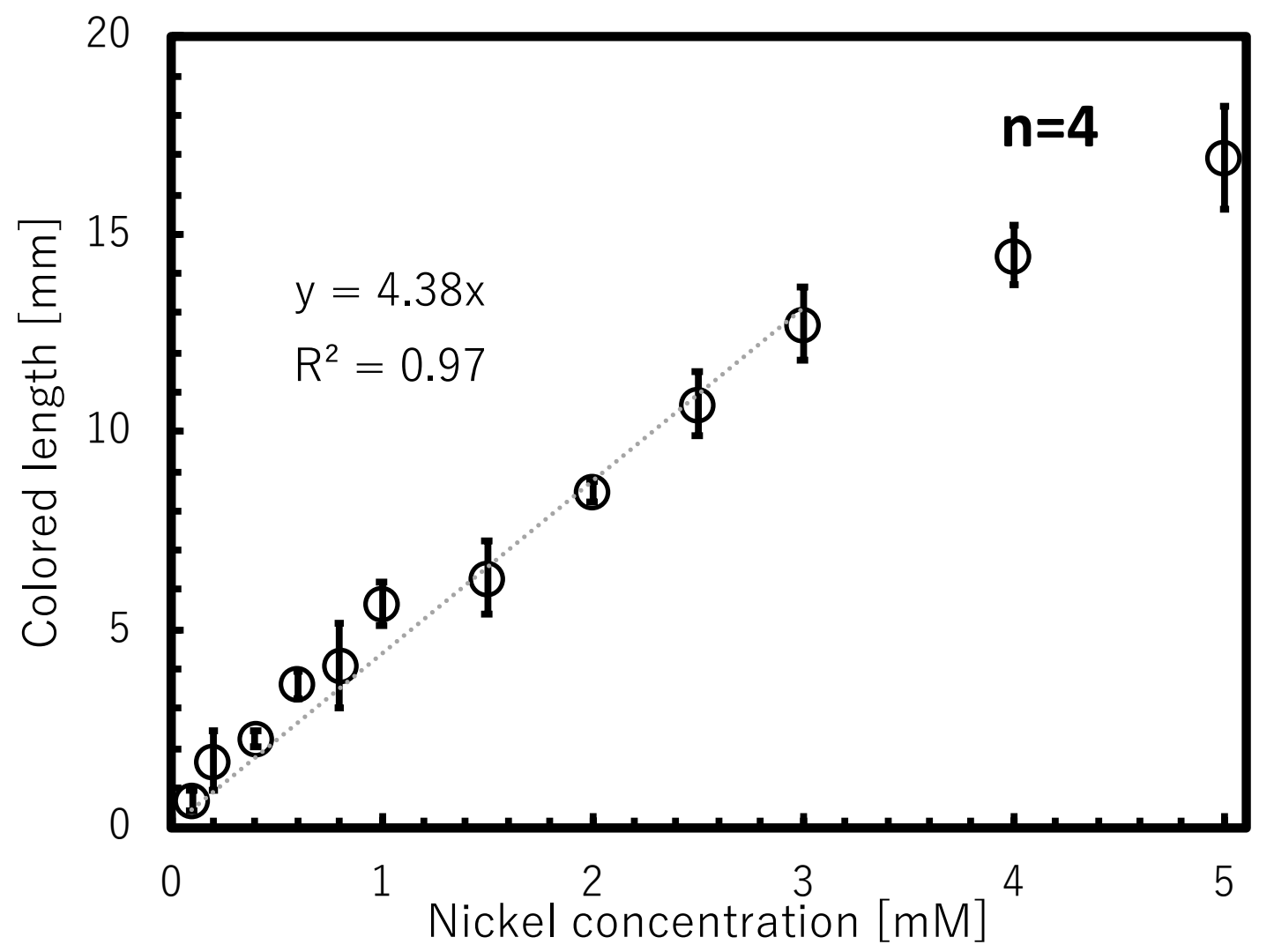

Figure S-9. Calibration curve of $\mathrm{Ni}^{2+}$ assay with $\mathrm{CD}-\mathrm{PADs}$ for the $\mathrm{SV}$ chamber with extended concentration range up to $5 \mathrm{mM}(\mathrm{n}=4)$. 


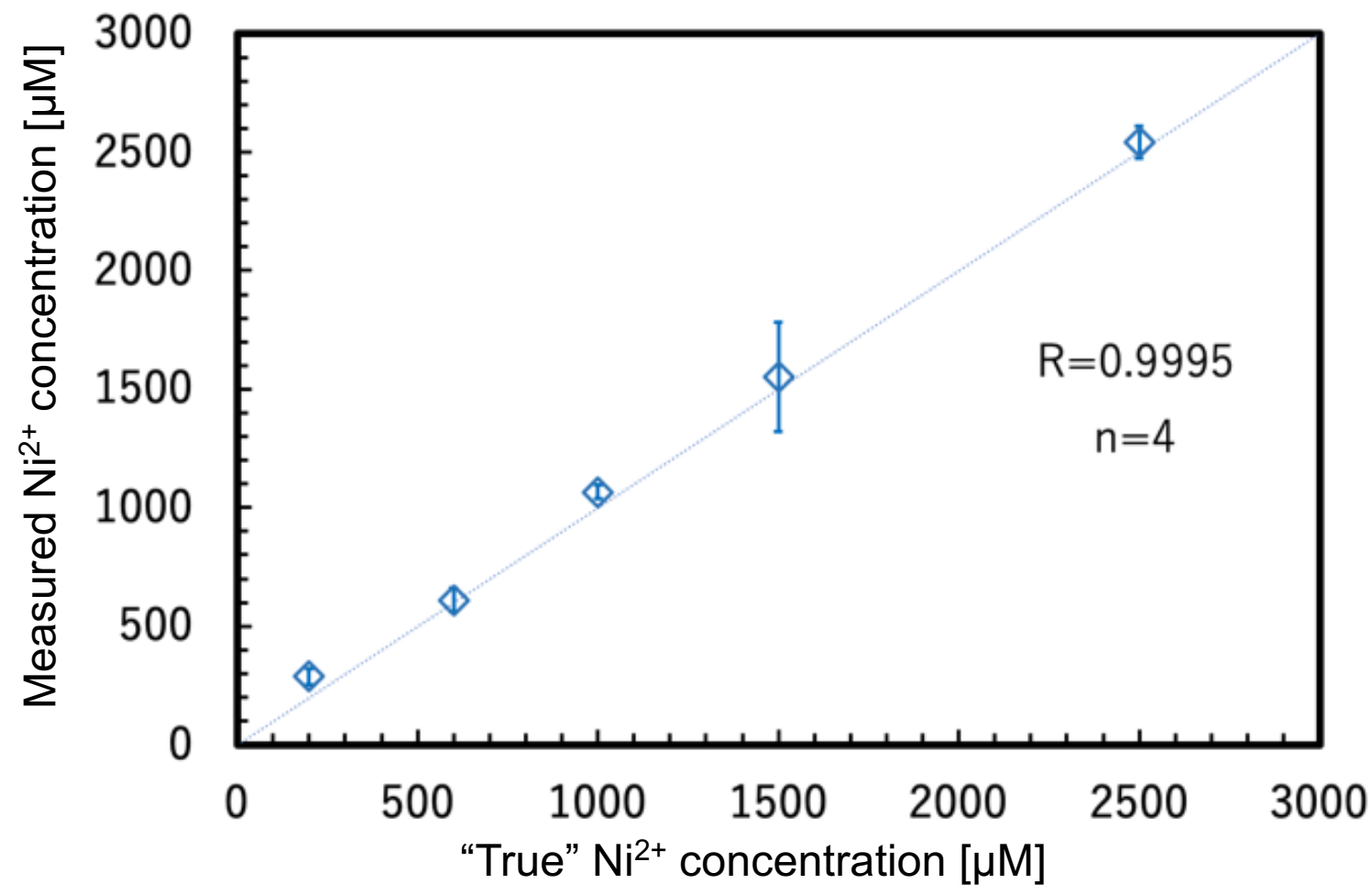

Figure S-10. Correlation between "true" and measured $\mathrm{Ni}^{2+}$ concentration values of aqueous standard solutions using CD-PADs with the MV chamber $(n=4)$. 


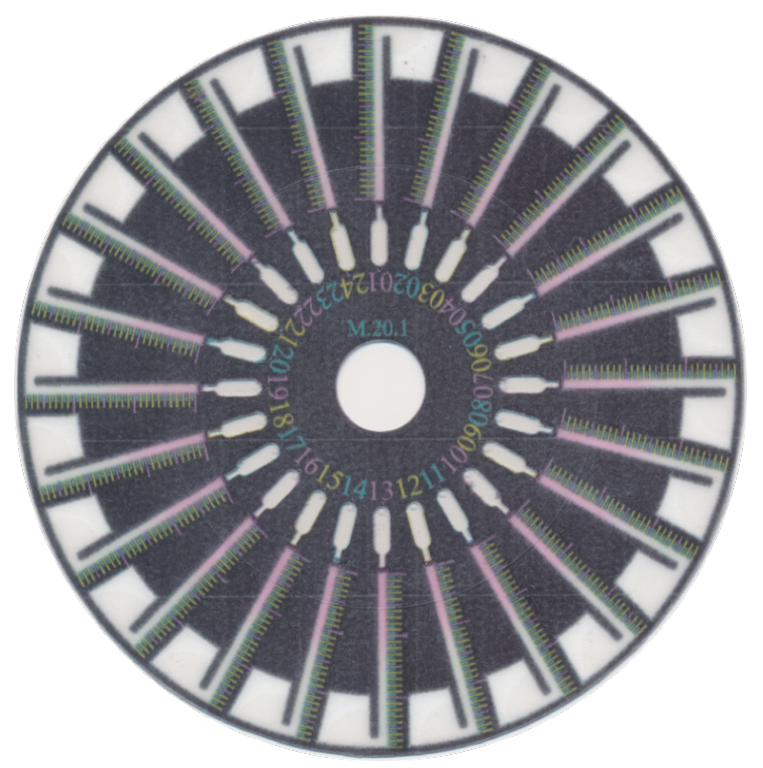

Figure S-11. Photograph of a CD-PAD after simultaneous assay of 24 identical samples (2 mM $\mathrm{NiCl}_{2}$ solutions) on a single disc. 
Table S-1. Pin functions of motor driver (Toshiba TA7291P).

\begin{tabular}{|l|l|l|}
\hline Pin\# & Function description & Connect to \\
\hline 1 & GND & Arduino pin GND (\#13) \\
\hline 2 & OUT1 & DVD player motor (\#15) \\
\hline 3 & Supply voltage for control & Arduino pin 3 (\#9) \\
\hline 4 & IN1 & Arduino pin 2 (\#10) \\
\hline 5 & IN2 & Arduino pin 1 (\#11) \\
\hline 6 & Supply voltage for logic & Arduino pin 5V (\#12) \\
\hline 7 & Supply voltage for motor driver & Arduino pin 5V (\#12) \\
\hline 8 & OUT2 & DVD player motor (\#14) \\
\hline
\end{tabular}


Table S-2. Pin functions of Arduino Uno R3

\begin{tabular}{|l|l|l|}
\hline Pin\# & Function description & Connect to \\
\hline 9 & $\begin{array}{l}\text { Digital pin 3 for pulse width } \\
\text { modulation (PWM) }\end{array}$ & Motor driver supply voltage for control (\#3) \\
\hline 10 & Digital pin 2 & Motor driver IN1 (\#4) \\
\hline 11 & Digital pin 1 & Motor driver IN2 (\#5) \\
\hline 12 & $5 \mathrm{~V}$ & $\begin{array}{l}\text { Motor driver supply voltage for logic \& } \\
\text { motor driver (\#6 \& \#7) }\end{array}$ \\
\hline 13 & GND & Motor driver GND (\#1) \\
\hline
\end{tabular}


Table S-3. Optimized rotation protocol for each type of chamber

\begin{tabular}{|c|c|c|}
\hline Chamber type & First step for sample introduction & Second step for flow acceleration \\
\hline SV/MV & $206 \mathrm{rad} / \mathrm{s}$ for $1 \mathrm{~min}$ & $266 \mathrm{rad} / \mathrm{s}$ for $0.5 \mathrm{~min}$ \\
\hline $\mathrm{LV}$ & $206 \mathrm{rad} / \mathrm{s}$ for $1 \mathrm{~min}$ & $266 \mathrm{rad} / \mathrm{s}$ for $4 \mathrm{~min}$ \\
\hline
\end{tabular}


Table S-4. Influence of sample volume on colored length and reproducibility for each type of chamber $(n=4)$

\begin{tabular}{|c|c|c|c|}
\hline Sample introduction & Colored length $[\mathrm{mm}]$ & SD $[\mathrm{mm}]$ & $\mathrm{CV}[\%]$ \\
\hline $3 \mu \mathrm{L}$ pipette & 5.5 & 1.64 & 30.1 \\
\hline SV & 8.8 & 0.92 & 10.5 \\
\hline $6 \mu \mathrm{L}$ pipette & 11.6 & 0.77 & 6.61 \\
\hline $\mathrm{MV}$ & 13.4 & 0.98 & 3.62 \\
\hline LV & 17.8 & 0.75 & 4.21 \\
\hline
\end{tabular}


Table S-5. LODs for nickel ion assays performed on CD-PADs with different sample metering chambers

\begin{tabular}{|l|l|l|l|}
\hline Chamber type & LOD $[\mu \mathrm{M}]$ & LOD $[\mathrm{ng}]$ & $\mathrm{CV}_{\text {avg }}[\%]$ \\
\hline SV & 196 & 53.0 & 14.1 \\
\hline MV & 107 & 44.1 & 10.5 \\
\hline LV & 95.0 & 51.8 & 8.10 \\
\hline
\end{tabular}


Table S-6. Benchmark of analytical performance. ${ }^{1-3}$

\begin{tabular}{|l|r|c|c|r|r|}
\hline \multirow{2}{*}{ Works } & \multicolumn{2}{|c|}{ LOD } & CV & Sample volume & Assay time \\
\cline { 2 - 6 } & $\mu \mathrm{M}$ & $\mathrm{ng}$ & \multicolumn{1}{c|}{$\%$} & \multicolumn{1}{c|}{$\mathrm{L}$} & \multicolumn{1}{c|}{$\mathrm{min}$} \\
\hline $\begin{array}{l}\text { Distance-based } \\
\text { thread device }^{1}\end{array}$ & 852 & 175 & N/A & $\begin{array}{r}\mathbf{2} \text { (polyester) } \\
\mathbf{3 . 5} \text { (cotton) }\end{array}$ & N/A \\
\hline Distance-based PAD $^{2}$ & 113.6 & 100 & $\mathbf{6 . 6}$ & 15 & $\sim 30$ \\
\hline Dip-and-read PAD $^{3}$ & 200 & N/A & $\mathbf{8 . 0}$ & N/A & $\sim 10$ \\
\hline This work (LV) & $\mathbf{9 5}$ & $\mathbf{5 1 . 8}$ & $\mathbf{8 . 1}$ & $\sim 9.5$ & 5 \\
\cline { 2 - 6 }$(\mathrm{MV})$ & $\mathbf{1 0 7}$ & $\mathbf{4 4 . 1}$ & 10.5 & $\sim 7$ & 1.5 \\
\cline { 2 - 6 }$(\mathrm{SV})$ & 196 & $\mathbf{5 3 . 0}$ & 14.1 & $\sim 4.5$ & 1.5 \\
\hline
\end{tabular}


Table S-7. Benchmark of cost.

\begin{tabular}{|c|c|c|c|c|}
\hline \multirow{2}{*}{ Works } & \multicolumn{2}{|c|}{ Equipment (reusable) } & \multicolumn{2}{|c|}{ Consumables (disposable) } \\
\hline & Name & Price (USD) & Name & Price (USD) \\
\hline \multirow{3}{*}{$\begin{array}{r}\text { Distance-based } \\
\text { thread device }^{1}\end{array}$} & \multirow{3}{*}{ Micropipette } & \multirow{3}{*}{$100-500$} & TADs & Not calculated \\
\hline & & & Tips & 0.02 \\
\hline & & & Tube & 0.02 \\
\hline \multirow{3}{*}{$\begin{array}{r}\text { Distance-based } \\
\text { PAD }^{2}\end{array}$} & \multirow{3}{*}{ Micropipette } & \multirow{3}{*}{$100-500$} & TADs & Not calculated \\
\hline & & & Tips & 0.02 \\
\hline & & & Tube & 0.02 \\
\hline \multirow{2}{*}{$\begin{array}{r}\text { Dip-and-read } \\
\text { PAD }^{3}\end{array}$} & \multirow{2}{*}{$\begin{array}{r}\text { 3D printed resin cassette } \\
\text { Tweezer }\end{array}$} & \multirow{2}{*}{$\begin{array}{r}10-20 \\
<1\end{array}$} & & \multirow{2}{*}{$\begin{array}{r}\mathbf{0 . 0 1 1} \\
0.35\end{array}$} \\
\hline & & & $(15 \mathrm{~mL})$ & \\
\hline \multirow[t]{3}{*}{ This work } & DVD drive pickup unit & $<1$ & PADs & $<0.013$ \\
\hline & Microcomputer & $<7$ & $\begin{array}{r}\text { Sample tube } \\
(1.5 \mathrm{~mL})\end{array}$ & 0.02 \\
\hline & Other electronics & $<5$ & Plastic pipette & 0.05 \\
\hline
\end{tabular}


Table S-8. Assay results for "unknown" aqueous $\mathrm{Ni}^{2+}$ solutions obtained with CD-PADs (MV sample metering chamber; $n=4$ )

\begin{tabular}{|r|r|r|r|}
\hline True Value $[\mu \mathrm{M}]$ & Measured value $[\mu \mathrm{M}]$ & Error [\%] & CV [\%] \\
\hline 200 & 286 & 43.0 & 12.0 \\
\hline 600 & 610 & 1.6 & 8.0 \\
\hline 1000 & 1065 & 6.5 & 2.7 \\
\hline 1500 & 1553 & 3.5 & 14.8 \\
\hline 2500 & 2542 & 1.7 & 2.6 \\
\hline & Average & 11.3 & 8.0 \\
\hline
\end{tabular}




\section{References}

(1) Nilghaz, A.; Ballerini, D. R.; Fang, X.-Y.; Shen, W. Semiquantitative Analysis on Microfluidic Thread-Based Analytical Devices by Ruler. Sens. Actuators B Chem. 2014, $191,586-594$.

(2) Cate, D. M.; Noblitt, S. D.; Volckens, J.; Henry, C. S. Multiplexed Paper Analytical Device for Quantification of Metals Using Distance-Based Detection. Lab. Chip 2015, 15 (13), $2808-2818$.

(3) Yamada, K.; Citterio, D.; Henry, C. S. "Dip-and-Read" Paper-Based Analytical Devices Using Distance-Based Detection with Color Screening. Lab. Chip 2018, 18 (10), 1485-1493. 